guidelines of the British Hyperlipidaemia Association. Br Med F 1987;295: 1245-6.

7 Austin AA. Plasma triglyceride as a risk factor for coronary heart disease. $A m \mathcal{F}$ Epidemiol 1989;129:249-59.

8 Hulley SH, Rosenman RH, Bawol RD, Brand RJ. Epidemiology as a guide to clinical decisions. $N$ Engl f Med 1980;25:1383-9.

9 Castelli WP. The triglyceride issue: a view from Framingham. Am Heart $f$ 1986;112:432-7.

10 National Education Program Expert Panel. Report of the national cholesterol education program expert panel on detection and treatment of high blood cholesterol in adults. Arch Intern Med 1988;148:36-69.

11 Lewis B, Assmann G, Mancini M, Stein Y, eds. Handbook of coronary hear disease prevention. London: Current Medical Literature, 1989.

12 Gordon T, Kannel WB, Castelli WP, Dawber TR. Lipoproteins, cardiovascular disease, and death. The Framingham study. Arch Intern Med 1981;141:1123-31.

13 Pocock SJ, Shaper AG, Phillips AN. Concentrations of high density lipoprotein cholesterol, triglycerides, and total cholesterol in ischaemic heart disease. BrMed f 1989;298:998-1002.

14 Mann JI, Lewis B, Shepherd J, et al. Blood lipid concentrations and other cardiovascular risk factors: distribution, prevalence, and detection in Britain. Br Med f 1988;296:1702-6.

15 Burstein M, Scholnick HR, Morfin R. Rapid method for the isolation of lipoproteins from human serum by precipitation with polyanions. $\mathcal{F}$ Lipid Res 1970;11:583-95

16 Castelli WP. Reversing the course of atherosclerosis-a view from Framingham. Kalamazoo, Michigan: Upiohn, 1989.
17 Royal College of Physicians. Obesity. $\mathcal{f} R$ Coll Physicians Lond 1983;17:5-65. 18 WHO Study Group. Diabetes mellitus. Geneva: World Health Organisation, 1985.

19 Anonymous. SPSSX user's guide. 3rd ed. New York: McGraw-Hill, 1988.

20 Wilson EB. Probable inference. The law of succession and inference. Fournal of the American Statistical Association 1927;22:209-12.

21 Lenter C, ed. Geigy scientific tables 2. Basel: Ciba-Geigy, 1982.

22 Assman G, Schulte H. Procam trial. Zurich: Panscientia Verlag, 1986.

23 National Heart, Lung, and Blood Institute Consensus Development Panel. Treatment of hypertriglyceridemia. FAMA 1984;251:1196-200.

24 Jacobs DR, Barrett-Conor E. Retest reliability of plasma cholesterol and triglycerides. Am J Epidemiol 1982;6:878-8

25 Reaven GM. Role of insulin resistance in human disease. Diabetes 1988;37 $1595-607$

26 Fuh MM-T, Shieh S-M, Wu D-A, Chen YD-I, Reaven GM. Abnormalities of carbohydrate and lipid metabolism in patients with hypertension. Arch Intern Med 1987;147:1035-8.

27 Anonymous. Type 2 diabetes or NIDDM: looking for a better name [Editorial]. Lancet 1989;i:589-91.

28 Jacobs DR, Mevane IL, Bangdiwala SI, Criqui MH, Tyroler HA. High density lipoprotein cholesterol as a predictor of cardiovascular disease mortality in men and women: the follow-up study of the Lipid Research Clinics prevalence study. Am $\mathcal{F}$ Epidemiol 1990;131:32-47.

(Accepted 16 fuly 1990

\title{
Atenolol in essential hypertension during pregnancy
}

\author{
Lucy Butters, Susan Kennedy, Peter C Rubin
}

\section{Abstract \\ Objective-To determine the effect of atenolol on the outcome of pregnancy in women with essential hypertension.}

Design-Prospective, randomised, double blind, placebo controlled study.

Setting-Hospital clinic.

Patients - 33 Women with mild essential hypertension (systolic blood pressure $140-170 \mathrm{~mm} \mathrm{Hg}$ or diastolic pressure $90-110 \mathrm{~mm} \mathrm{Hg}$ on two occasions at least 24 hours apart) consecutively referred to two obstetric medical clinics. Four patients in the placebo group were withdrawn from the study: control of blood pressure was inadequate in two, one developed breathlessness, and one changed her mind about participating. The mean gestation in the 29 remaining women on entry to the study was 15.9 weeks.

Main outcome measures-Blood pressure and birth weight.

Intervention-14 Women received placebo. 15 Women received atenolol $50 \mathrm{mg}$ daily initially, increasing until either the blood pressure was $<140 / 90 \mathrm{~mm} \mathrm{Hg}$ or a dose of $200 \mu \mathrm{g}$ daily was reached.

Results - The mean blood pressure on entry was $148 / 86 \mathrm{~mm} \mathrm{Hg}$ in the group given atenolol and 144/86 $\mathrm{mm} \mathrm{Hg}$ in the group given placebo. During treatment the mean diastolic pressure was significantly reduced by atenolol compared with placebo (to $74 v 81 \mathrm{~mm}$ $\mathrm{Hg}$; difference in means ( $95 \%$ confidence interval) $\mathbf{7 . 0}(2.9$ to 10.0$) \mathrm{mm} \mathrm{Hg})$ but the effect on systolic pressure was marginal (132 $v 136 \mathrm{~mm} \mathrm{Hg} ; 4.0(-1.4$ to 8.6) $\mathrm{mm} \mathrm{Hg}$ ). Babies in the atenolol group had a significantly lower birth weight than those in the placebo group ( $2620 \mathrm{~g} v 3530 \mathrm{~g} ; 910$ (440 to 1380$) \mathrm{g}$ ).

Conclusion-Atenolol given from the end of the first trimester in patients with mild hypertension is associated with intrauterine growth retardation. When taken in conjunction with the results of a previous study in which methyldopa was given these findings indicate that benefit is unlikely to result from treating mild essential hypertension in pregnancy.

\section{Introduction}

The value of antihypertensive drugs in managing mild to moderate essential hypertension during pregnancy is unclear. A study by Redman et al in the 1970s found that the outcome of pregnancy was better in a group who received methyldopa than in a group who did not receive any treatment. ${ }^{1}$ It was difficult, however, to ascribe the better outcome to the reduction in blood pressure, and Redman et al concluded that perhaps an unidentified pharmacological effect of methyldopa was responsible.

Extrapolating from this hypothesis, we argued that if it was a reduction in blood pressure that was responsible for the better outcome then a different antihypertensive agent would have the same beneficial effect. We showed that atenolol given to women who develop hypertension in the third trimester successfully lowers blood pressure and usefully prolongs pregnancy, with a consequent reduction in perinatal morbidity. ${ }^{2}$ In the present study we assessed the value of atenolol in women whose pregnancies were complicated by essential hypertension.

\section{Patients and methods}

The randomised, placebo controlled, double blind study was approved by the research and ethical committee of Greater Glasgow Health Board Northern District. Thirty three women who were consecutively referred to the obstetric medical clinics at Stobhill General Hospital and the Queen Mother's Hospital for management of essential hypertension were studied. The criteria for entry to the study were either a systolic blood pressure between 140 and $170 \mathrm{~mm} \mathrm{Hg}$ or a diastolic blood pressure (Korotkoff phase $\mathrm{V}$ ) between 90 and $110 \mathrm{~mm} \mathrm{Hg}$ on two occasions separated by at least 24 hours. Recruitment took place at between 12 and 24 weeks' gestation. Women were excluded from the study if they had any of the usual contraindications to use of a $\beta$ blocker.

For those women who received active treatment the starting dose of atenolol was $50 \mathrm{mg}$ daily and the number of tablets was increased at each visit until either the blood pressure was $<140 / 90 \mathrm{~mm} \mathrm{Hg}$ or a dose of $200 \mathrm{mg}$ daily was reached. The patients were seen at intervals of four weeks until they were 28 weeks pregnant, then every two weeks until they were 36 weeks pregnant, and then weekly until delivery. Babies were assessed at birth and at 12 months of age.

Data were analysed by $t$ test. In the case of blood 
pressure, all readings after entry to the trial were averaged and the means for the two groups were compared. We had originally intended to recruit a larger number of women, but during the course of the study the principal investigator (PCR) left Glasgow and we thought it impractical to continue. The treatment codes were not broken until the last patient delivered.

\section{Results}

Three women in the placebo group were withdrawn from the study, because of inadequate control of blood pressure (two) and breathlessness (one), and one woman in the atenolol group changed her mind about participating before taking any tablets. No additional drugs were used by the 29 women who remained in the study. Analysis of data on these 29 patients ( 15 treated with atenolol and 14 with placebo) showed that the two groups were well matched with regard to average gestation at entry $(15.8$ and 15.9 weeks respectively) and average blood pressure at entry (144/86 and 148/86 $\mathrm{mm} \mathrm{Hg}$ respectively). The table shows the patients' blood pressure after entry to the trial. Mean diastolic pressure was significantly reduced by atenolol, but the effect on systolic pressure was marginal.

One stillbirth occurred in the atenolol group. Figure 1 shows the birth weights of the babies and figure 2 the placental weights. The babies in the atenolol group

Mean blood pressure after entry to study and paediatric measurements at 12 months of age

\begin{tabular}{|c|c|c|c|c|}
\hline & $\begin{array}{l}\text { Placebo } \\
\text { group }\end{array}$ & $\begin{array}{l}\text { Atenolol } \\
\text { group }\end{array}$ & $\begin{array}{c}\text { Difference } \\
(95 \% \text { confidence interval })\end{array}$ & $\mathrm{p}$ Value \\
\hline \multicolumn{5}{|l|}{ Blood pressure after entry $(\mathrm{mm} \mathrm{Hg})$ : } \\
\hline Systolic & 136 & 132 & $4.0(-1.4$ to 8.6$)$ & 0.08 \\
\hline Diastolic & 81 & 74 & $7.0 \quad(2.9$ to 10.0$)$ & 0.001 \\
\hline \multicolumn{5}{|l|}{ Paediatric measurements at 12 months: } \\
\hline Weight $(\mathrm{kg})$ & $9 \cdot 82$ & $9 \cdot 26$ & $0.56(-1.71$ to 0.61$)$ & $0 \cdot 17$ \\
\hline Length $(\mathrm{cm})$ & $75 \cdot 3$ & $74 \cdot 3$ & $1.0(-3.7$ to 1.8$)$ & $0 \cdot 24$ \\
\hline Occipitofrontal circumference $(\mathrm{cm})$ & $46 \cdot 8$ & $46 \cdot 4$ & $0.4(-2.0$ to 1.2$)$ & 0.2 \\
\hline
\end{tabular}

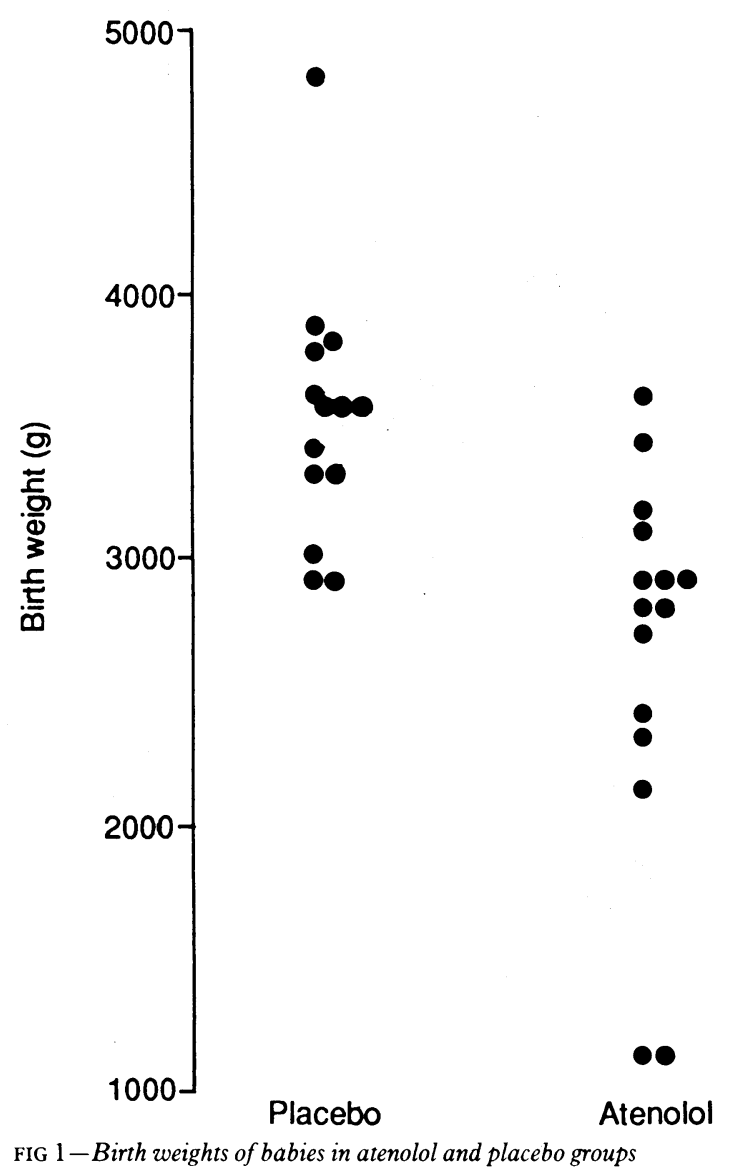

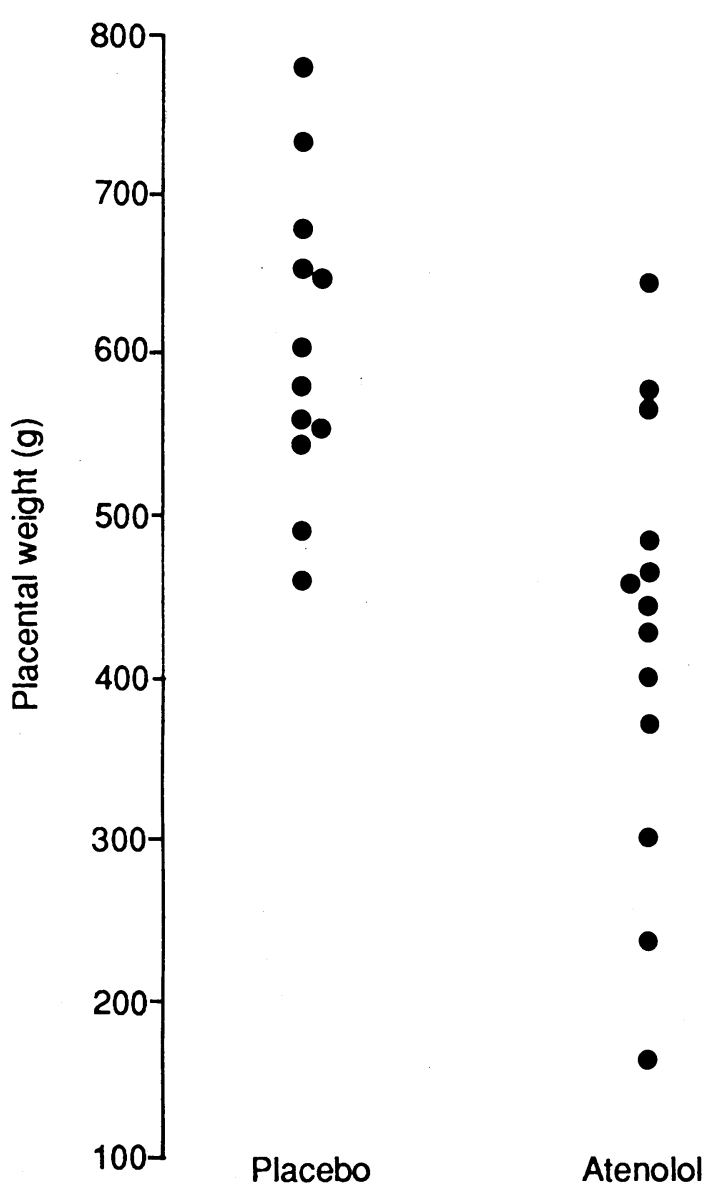

FIG 2-Placental weights in atenolol and placebo groups. Two data points in each group are missing owing to information not being recorded in case sheets

were significantly smaller than those in the placebo group with a mean weight of $2620 \mathrm{~g}$ and $3530 \mathrm{~g}$ respectively (difference in means $(95 \%$ confidence interval) 910 (440 to 1380$) \mathrm{g} ; \mathrm{p}<0.001)$. The weights of five of the 15 babies in the atenolol group were below the fifth centile for gestational age, and 10 were below the 10th centile. In the placebo group the weight of only one baby was below the 25 th centile. Similar differences between groups were observed in the mean placental weight, which was $442 \mathrm{~g}$ in the atenolol group and $635 \mathrm{~g}$ in the placebo group (difference in means 193 (103 to 282) $\mathrm{g} ; \mathrm{p}<0.002$ ). The difference between the groups persisted when the data were analysed on an intention to treat basis: birth weights in the atenolol and placebo groups were $2670 \mathrm{~g}$ and $3470 \mathrm{~g}$ respectively $(\mathrm{p}<0.001)$ and placental weights $454 \mathrm{~g}$ and $633 \mathrm{~g}$ respectively $(\mathrm{p}<0 \cdot 001)$.

No explanation for the difference in placental and neonatal weights could be found in terms of blood pressure, heart rate, or dose of atenolol. The gestational age at delivery was similar in the placebo and atenolol groups ( 39.5 and 38.5 weeks respectively), and the difference in birth weight persisted when adjusted for gestational age.

The table shows physical measurements for the infants at 12 months of age; the differences between the groups had resolved.

\section{Discussion}

The use of $\beta$ blockers during pregnancy has never been free from controversy. ${ }^{3}$ During the 1970 s a wide range of adverse fetal and neonatal effects including intrauterine growth retardation was ascribed to this group of drugs, particularly propranolol. ${ }^{4}$ Interpreting these early reports, however, was difficult because they were either case reports or retrospective analyses by review of charts. In addition, the reported cases were 
often of pregnancies with many major complications and it was difficult to distinguish between effects of the disease and effects of the drugs given.

Prospective studies have given a uniformly different picture with regard to fetal growth from that given by the early reports. Small uncontrolled studies of propranolol in hypertension, ${ }^{5}$ a study of a series of women taking propranolol for hypertrophic obstructive cardiomyopathy, ${ }^{6}$ and randomised comparisons of oxprenolol with methyldopa ${ }^{7-9}$ suggested that growth retardation was not a feature of treatment with $\beta$ blockers during pregnancy. In two double blind, randomised, placebo controlled studies of atenolol ${ }^{2}$ and metoprolol ${ }^{10}$ in pregnancy induced hypertension no difference in average birth weight was found between the groups given placebo and active treatment, and there was no excess of babies who were small for gestational age in groups given the $\beta$ blockers.

In contrast, our study provides unequivocal evidence that atenolol given to manage mild essential hypertension is associated with impaired fetal growth. The mechanism of this effect and the reasons for the difference in outcome between this and our earlier trial of atenolol ${ }^{2}$ are not clear, but several points are relevant.

Firstly, the women who entered this study had fairly mild hypertension. In particular, our recruitment of women who met either the criterion for systolic pressure or the criterion for diastolic pressure, but not necessarily both, resulted in several patients having a diastolic pressure $<90 \mathrm{~mm} \cdot \mathrm{Hg}$ at the start of the study. The women in our previous study of pregnancy induced hypertension had more severe, as well as mechanistically different, hypertension. Thus a possible explanation of our findings is that we were excessively lowering a blood pressure that was only slightly raised and that fetal perfusion was adversely affected. The blood pressures at entry, however, were not materially different from those in Redman et al's study of methyldopa, in which the group given early treatment had an average blood pressure on entry of $142 / 88 \mathrm{~mm} \mathrm{Hg}$ and similar reductions in pressure seem to have occurred. " As growth retardation was not seen in that study we infer that the atenolol itself, rather than the lowering of the blood pressure, was responsible for the unsatisfactory response to treatment.

Secondly, the women entered the present study at a mean of 15.9 (SD 2.8) weeks' gestation whereas the women entered our study of pregnancy induced hypertension at $33.8(4.9)$ weeks' gestation. Thus the women in the present study received treatment for about 18 weeks longer than those in our previous trial. Indeed, all the studies referred to above in which an adverse effect on growth was not seen (with the possible exception of the study of patients with cardiomyopathy, in which gestation was not stated) began treatment in the third trimester. The duration of treatment may therefore be a factor in the growth retardation.

Thirdly, we reported in our study of pregnancy induced hypertension that treatment with atenolol is associated with a significant and progressive fall in human placental lactogen concentration. ${ }^{12}$ We were unable to correlate this fall in concentration with the outcome of pregnancy and could not offer any explanation other than to discount interference with the assay in vitro. With the changing emphasis from biochemical to biophysical methods of fetal assessment human placental lactogen concentration is less commonly measured now than when we did our earlier study and we did not measure it in the present study.
We tended previously to discount the falling human placental lactogen concentration, though we accepted that it was unexplained, but our observations on fetal growth in the present study add new relevance to it. As human placental lactogen concentration is a measure, albeit of limited value, of placental function possibly atenolol impairs placental physiology in some way. The consequences of this impairment could be evident biochemically in the short term and become clear clinically with longer term treatment. Should this be the case, the mechanism by which atenolol exerts this effect is unclear. The effect of atenolol on variables of Doppler waveform indices is undecided, with present evidence being conflicting. ${ }^{1314}$ If our observations are the result of an effect of atenolol similar consequences would probably result from the use of any $\beta$ blocker with a similar pharmacodynamic profile. Our findings do not enable us to speculate on whether a $\beta$ blocker with intrinsic sympathomimetic activity would have a similar effect. The difference in the weight of the children between the two groups had resolved by 12 months, indicating that the changes were reversible.

The importance of the drug treatment in the one stillbirth that occurred is difficult to assess because the woman concerned had also had a stillbirth in her previous pregnancy, when she did not receive any drug treatment.

In conclusion, we are left with substantial uncertainties about the value of treating mild essential hypertension during pregnancy. The earlier findings of Redman $e t a l^{1}$ did not suggest a simple relation, if any, between controlling blood pressure with methyldopa and an improved outcome of pregnancy. The present study suggests that using atenolol in patients with mild essential hypertension leads to growth retardation. We therefore do not recommend the use of a $\beta$ blocker to treat hypertension early in pregnancy and suggest that benefits are unlikely to accrue from treating the milder forms of essential hypertension in pregnancy.

This work was supported by a grant from ICI Pharmaceuticals. LB and PCR were supported by the Wellcome Trust. Some of the data were presented at a meeting of the International Society for the Study of Hypertension in Pregnancy in Montreal in 1988.

1 Redman CWG, Beilin LJ, Bonnar J, Ounsted MK. Fetal outcome in trial of antihypertensive treatment pregnancy. Lancet 1976;ii:753-6.

2 Rubin PC, Butters L, Clark DM, et al. Placebo-controlled trial of atenolol in treatment of pregnancy-associated hypertension. Lancet 1983;i:431-4.

3 Rubin PC. Beta blockers in pregnancy. Br $\mathcal{F}$ Obstet Gynaecol 1987;94:292-4.

4 Rubin P. Beta blockers in pregnancy. N Engl F Med 1981;305:1323-6.

5 Rubin PC, Butters L, Low RA, Reid JL. Atenolol in the treatment of essential hypertension during pregnancy. Br $\mathcal{F}$ Clin Pharmacol 1982;14: $279-81$

6 Oakley GDG, McGarry K, Limb DG, Oakley CM. Management of pregnancy in patients with hypertrophic cardiomyopathy. Br Med f 1979;i:1749-50.

7 Gallery EDM, Saunders DM, Hunyor SN, Gyory AZ. Randomised comparison of methyldopa and oxprenolol for treatment of hypertension in comparison of methyldopa and oxpreno
pregnancy. $B r$ Med $f$ 1979;i:1591-4.

8 Gallery EDM, Ross MR, Gyory AZ. Antihypertensive treatment in pregnancy: analysis of different responses to oxprenolol and methyldepa. Br Med $\mathcal{Y}$ 1985;291:563-6.

9 Fidler J, Smith V, Fayers P, De Swiet M. Randomised controlled comparative study of methyldopa and oxprenolol in treatment of hypertension in pregnancy. Br Med F 1983;286:1927-30.

10 Wichman K, Ryulden G, Karlberg BE. A placebo controlled trial of metoprolol in the treatment of hypertension in pregnancy. Scand 7 Clin Lab Invest 1984;169:90-4.

11 Redman CWG, Beilin LJ, Bonnar J. Treatment of hypertension in pregnancy with methyldopa: blood pressure control and side effects. Br f Obstet Gynaecol 1977;84:419-26.

12 Rubin PC, Butters L, Clark D, et al. Obstetric aspects of the use in pregnancyassociated hypertension of the beta adrenoceptor antagonist atenolol. Am f Obstet Gynecol 1984;150:389-92.

13 Montan S, Liedholm H, Lingman G, Marsal K, Sjoberg NO, Solum T. Fetal and utero-placental haemodynamics during short-term atenolol treatment of
hypertension in pregnancy. Br O Obstet Gynaecol 1987;94:312-7.

14 Hanretty K, Whittle M, Rubin PC. Influence of atenolol on Doppler flow velocity waveforms in hypertensive human pregnancy [Abstract] f Hypertens 1987;5:767-8.

(Accepted 18 fuly 1990) 